\title{
THE IMPACT OF CORONAVIRUS (SARS-COV2) EPIDEMIC ON INDIVIDUALS MENTAL HEALTH: THE PROTECTIVE MEASURES OF PAKISTAN IN MANAGING AND SUSTAINING TRANSMISSIBLE DISEASE
}

\author{
Jaffar Abbas \\ Antai College of Economics and Management, School of Media and Communication, Shanghai Jiao Tong University, \\ Minhang District, Shanghai, China
}

received: 14.5 .2020

revised: 7.9 .2020

accepted: 29.9.2020

\section{SUMMARY}

Background: This study performed a focalized examination of the global impact of the coronavirus epidemic. This current review is one of the few kinds of research, which has sought to check the effect of the coronavirus on mental health issues and the need for psychological well-being in the standard population and patients in response to the global wake of the epidemic and its effects in Pakistan.

Subjects and methods: This study has utilized the data on coronavirus patients from the Ministry of Health, National Institute of Health Pakistan. The age of the confirmed coronavirus patients ranged from 12 to over 80 years, including international and local transmitters.

Results: Recorded data delivered by the National Institute of Health, Pakistan has quantified that the outbreak of coronavirus (SARS-CoV-2) entered Pakistan through international travelers. They carried the virus after they visited different countries, such as Saudi Arabia, Iran, Iraq, the USA, China, and European countries. By April 30, 2020, there were 16,473 confirmed cases of coronavirus. Total deaths are 361, with a mortality rate of $2.20 \%$, and ultimately recovered cases reported 4,105 with a percentage of 24.90\%. As of October 24, 2020, there were 327,063 confirmed cases of the COVID-19 in Pakistan, which posed vast social, economic, health, and environmental problems in the society. The epidemic has affected individuals across the country and confirmed patients in the country increased rapidly.

Conclusion: The government officials had initially estimated over 50,000 corona patents by April 30, which would be a great challenge; however, the situation remained under control because of suppression and smart-lockdown strategies by the Government. This study's findings reported that superior health facilities are required to treat the patients. This research review incorporated data generated by $\mathrm{NIH}$, and respondents are from all the regions of Pakistan, subsequently restricting its generalizability to experimental results.

Key words: global pandemic - COVID-19 - mental health - respiratory syndrome - coronavirus

\section{INTRODUCTION}

The coronavirus pandemic (SARS-CoV-2), a particular strain of the infectious disease, which explicitly instigates severe acute respiratory syndrome, surfaced in Wuhan by the end of December 2019. The government reported the fatality rate $2.20 \%$ in Pakistan (Abbas et al. 2019). The coronavirus pandemic rapidly spread across China and later across the world (Ahmed et al. 2020). The patients suffering from this infectious disease reported a fatality rate between 2-3 percent around the world (Wang et al. 2020), which is a bit higher than influenza; however, it is more contagious than severe acute respiratory syndrome (SARS) (Li et al. 2020). As of April 30, 2020, territories, states, and countries outside of China had reported infections to the World Health Organization (WHO), with an estimation of over 3.26 million active cases and a staggering death toll over 231,808 . In the next sixt months, the infected patients increased to over 42.84 million reported cases of coronavirus, with the deaths toll of more than 1.153 million. There are more than 31.596 million recovered cases from the transmittable disease, as of October 24, 2020, around the world.

The advent of the epidemic COVID-19 has also massively struck the economy of Pakistan. As of October 24, 2020, there are 327,063 confirmed cases of the COVID-19 in Pakistan, which posed enormous social, economic, health, and environmental problems in the society (Yoosefi Lebni et al. 2020). The pandemic has also affected the mental health of the older adults during isolation and lockdown phases (Shuja et al. 2020). Pharmaceutical companies have initiated their trials to develop a vaccine to treat COVID-19 patients, and there is a great race to bring effective vaccine in the market against COVID-19 disease (Su et al. 2020). The study of Johnson \& Mueller (2002) reported that last time the world encountered a similar global pandemic, which was the influenza outbreak (H1N1) of 1918 to 1920. With an estimated death rate recorded between 50 and 100 million and with several reported cases of mental health issues in its aftermath (Johnson \& Mueller 2002). 
As there is no appropriate cure, several countries are responding to the pandemy through a combination of confinement and mitigation strategies (Liu 2020). It is helpful to defer the significant flow of patients and curtail the demand for hospital admissions while safeguarding the most vulnerable from infection, such as the elderly and patients with comorbidities (Folkman \& Greer 2000). However, this method has disrupted the psychosocial life of the public, thus creating an impending sense of fear and provoking anxiety and similar mental issues (Xiang et al. 2020). While many developed countries have the resources to deal with financial and social crises, they find it challenging to deal with these issues (Abbas et al. 2019). Third world countries, such as Pakistan, which has a more significant portion of the population consisting of laborers and people with low wages, are facing the full brunt of the outbreak. The Government of Pakistan has extended the complete shutdown of various cities within the country until May 09, 2020, which is leading to frustration, anger, depression, and several other psychological disorders (Ahmad et al. 2020).

\section{METHOD}

This study has utilized the data on coronavirus patients delivered by NIH, Ministry of Health Pakistan. The age of the confirmed patients ranged from 12 to over 80 years, including international and local transmitters.

\section{RESULTS}

Recorded data originated from NIH has specified that the outbreak of coronavirus entered Pakistan through international travelers who came to Pakistan. They carried the virus after they visited different countries, such as Saudi Arabia, Iran, Iraq, the USA, China, and
European countries. By April 30, 2020, there are over 16,473 confirmed cases of coronavirus in Pakistan. The epidemic has affected individuals across the country, and confirmed patients in the country had reported a rapid increase within three weeks. This sharp increase has happened because of local transmission, which has increased over $66 \%$, an alarming situation across Pakistan. See Figure 1 below to understand the present situation in Pakistan.

The facts reported that there were 8,418 confirmed patients affected by coronavirus by April 19, 2020, in all the provinces in Pakistan. However, there are 16,473 confirmed cases with total deaths 361 , with a mortality rate of $2.20 \%$, and ultimately recovered cases reported 4,105 with a percentage of $24.90 \%$. The people are under high stress and facing mental health problems because of the stress (Halle et al. 2020). The situation has gone worst, as public hospitals have limited resources to admit a large number of patients. On the contrary, private hospitals are quite expensive and mostly out of reach from ordinary people because the earning capacity is lower for the majority of the population. Figure 2 below shows overall confirmed cases and daily new coronavirus cases in Pakistan. The primary reason was the local transmission, as people have not followed lockdown imposed by the central Government. Zaireen is the international religious travelers who visited Saudi Arabia, Iran, and Iraq to pay their religious duties. NonZairean are local people such as "Tableeghi Jamaat" as they traveled across the country and became the carrier of coronavirus. They are the reason for local transmission according to the government facts.

Ominously, coronavirus diseasehas emerged in developed countries, and the influence of the coronavirus pandemic reported the worst consequences. The modelers' dealing with contagious illnesses affiliated with Imperial College London have warned that ignoring mitigation strategy might infect seven billion individuals worldwide,

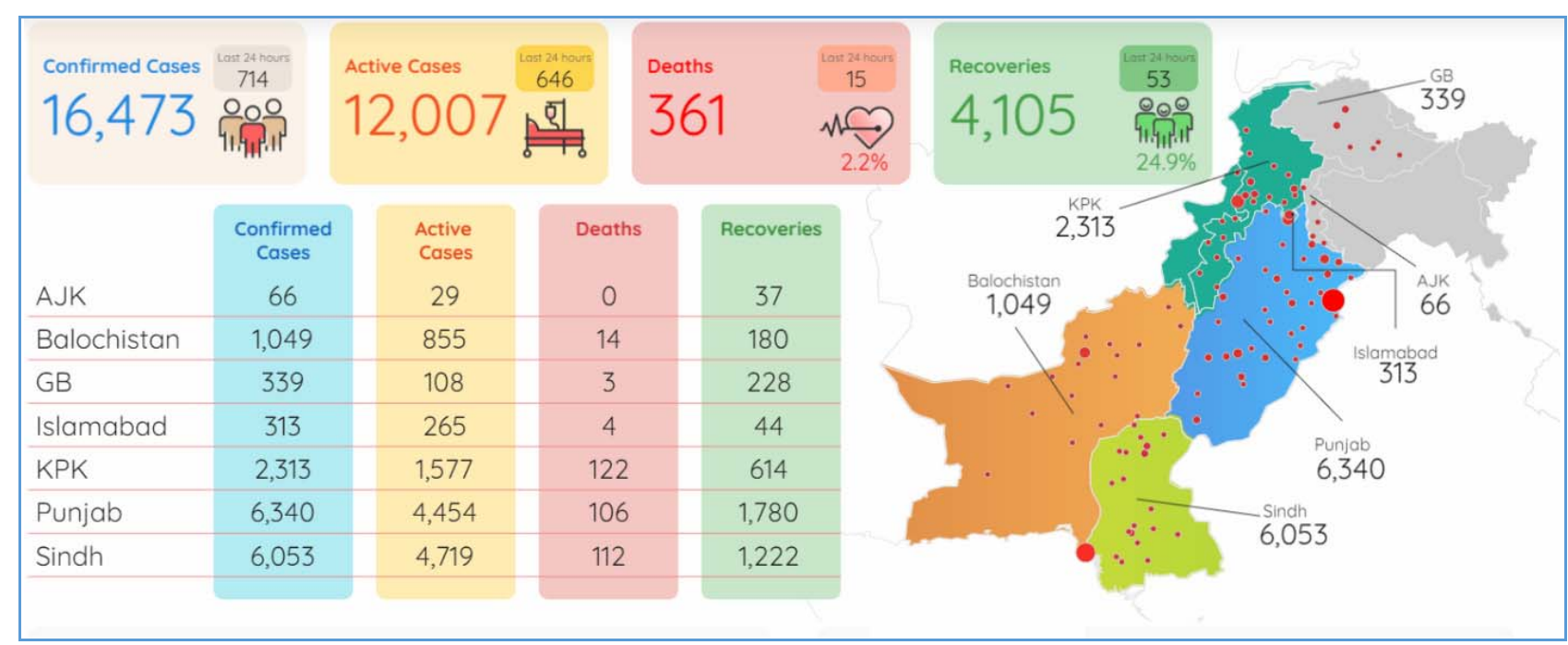

Source: National Health Institute (NIH), Ministry of Health, Pakistan

Figure 1. Total patients with Coronavirus across Pakistan 


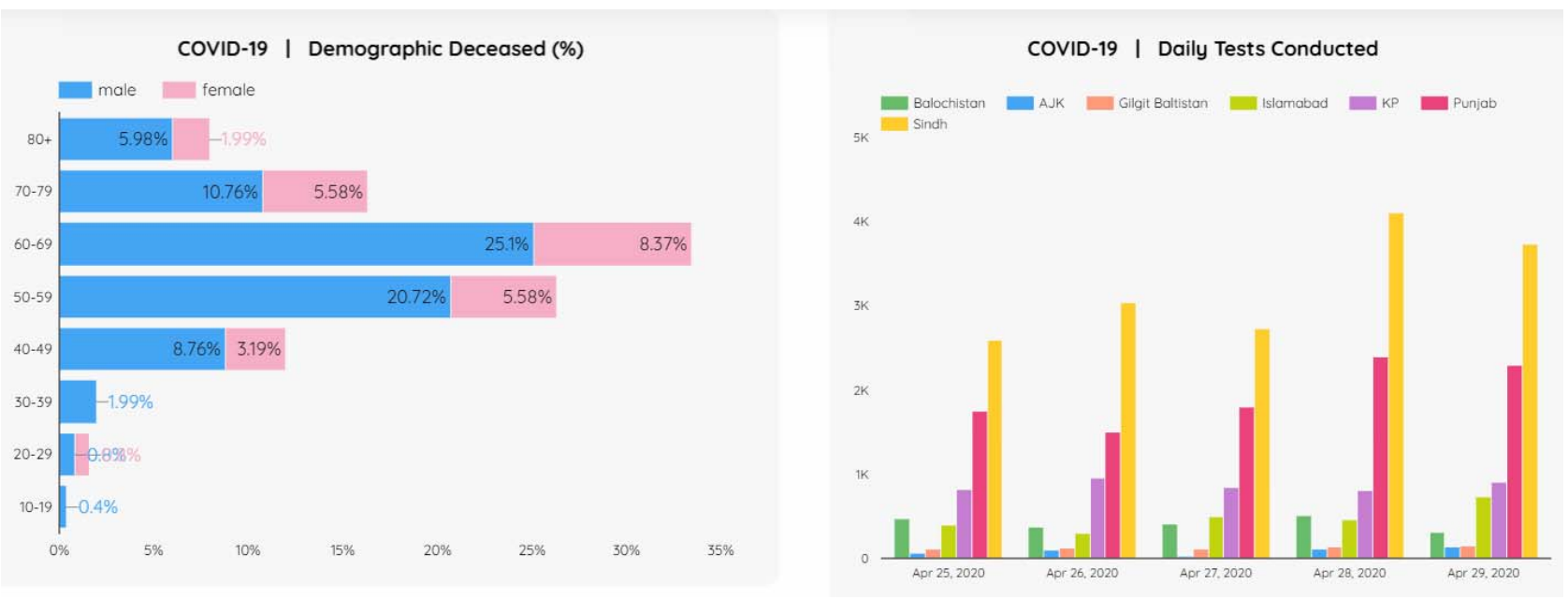

Source: National Health Institute (NIH), Ministry of Health, Pakistan

Figure 2. Patients of coronavirus Demographic Deceased and Daily Testing Pakistan
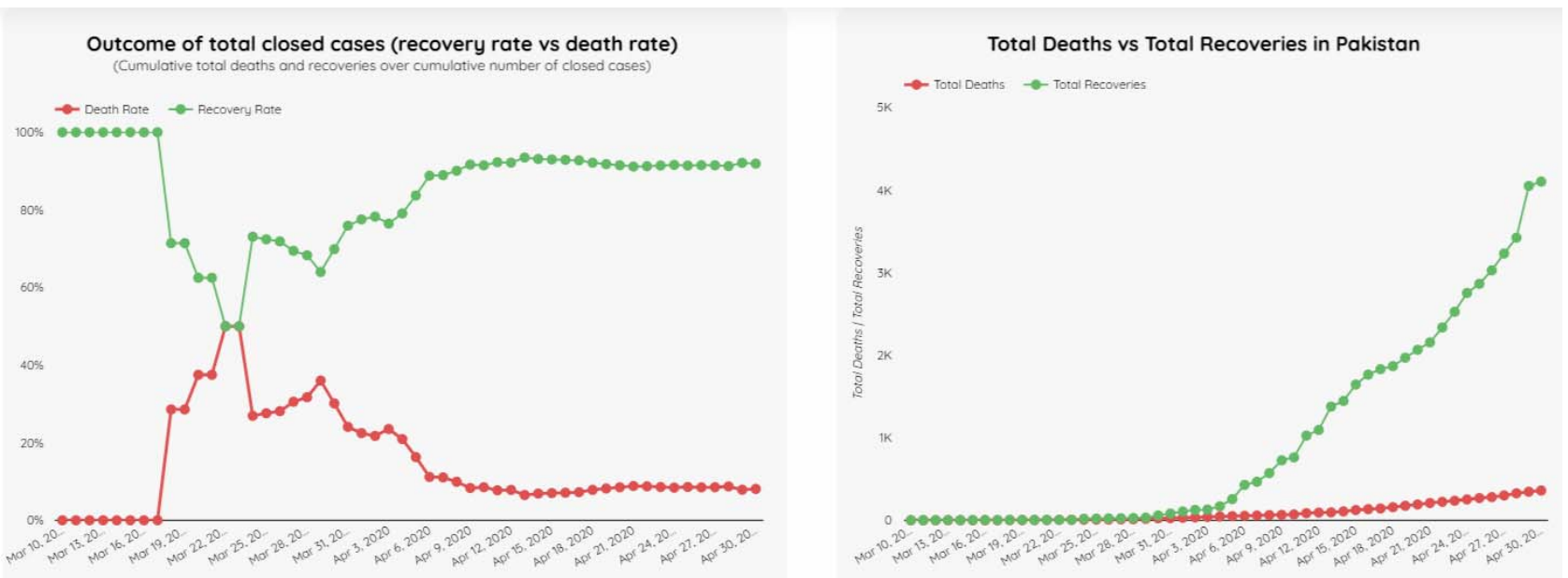

Source: National Health Institute (NIH), Ministry of Health, Pakistan

Figure 3. Coronavirus Patients, Recovery VS Death Rate in Pakistan

and deaths toll may reach 40 million by the end of 2020 worldwide. Therefore, a sustainable early mitigation strategy in such sever global health emergencies is crucial in blunting the outbreak to save human lives. The coronavirus epidemic has hit over 210 countries and territories worldwide so far; however, Italy was the first country from Europe, which was most severely pretentious with confirmed patients of coronavirus and numbers surpassed China by greater than three times (Silverio et al. 2020). The outbreak was declared out of control in the most affected countries, and the public criticized governments' responses as systematic failures in absorbing this epidemic rapidly and effectively (Shuja et al. 2020).

\section{The Impact of COVID-19 outbreak and Global Public Mental Health Issues}

Mental health is a serious problem in the advent of COVID-19 and numerous studies have indicated a direct link between chronic diseases, including human immunodeficiency virus (HIV) and tuberculosis (Gale et al. 2018) with mental disorders such as depression (Mason \& Lyons 2003) in the general population (Chang \& Ashcraft 2020). Similarly, studies conducted during and after epidemics (Van Den Heuvel et al. 2013), including SARS in 2003 and Ebola in 2014 (Reperant \& Osterhaus 2017), reported that diseases induced fear with over-reactive behavior among the public (Shultz et al. 2016). In addition to this, several psychiatric disorders, for instance, stress, anxiety, post-traumatic stress disorder, and depression disorders (Kott \& Limaye 2016), showed a link with such diseases (Mak et al. 2009), mainly in survivors and healthcare workers (Maya-Mondragon et al. 2019). Although the coronavirus impact on public mental health needs more systematic study, however, there are expected significant effects based on the recent public reaction (Cao et al. 2020). Based on this argument, opinion, and previous experiences on China's National Health Commission took significant steps dated January 26, 2020, and released a notification, which stipulated guidelines for 
emergency psychosocial disaster interventions (Liu et al. 2020). It helped in reducing the psychosocial consequences of the coronavirus outbreak, with psychological teams consisting of psychiatrists, mental health professionals, and psychological support hotlines (Zhao et al. 2020). The department of mental health of WHO released the substance instructions on March 18, 2020, and provided an outline to address the mental health issues and psychological well-being (Huang et al. 2020) of the standard populations and specific communities (Zhao et al. 2020). These instructions are useful for psychiatrists and mental health professionals in dealing with patients and the general population, and it assists in understanding the likely effects of Covid-19-. These guidelines are helpful for patients, families, and other communities in facing the challenging and the newest threats of coronavirus in productive ways (Cortegiani et al. 2020).

\section{The COVID-19, social distancing and negative behaviors}

As highlighted by the WHO in their mental health outline, the stigmatization and scapegoating of affected persons, health care professionals, and authority figures is a widespread occurrence during epidemics (Rubin \& Wessely 2020). Unfortunately, this trend has continued during the current outbreak of coronavirus as several people of Asian lineage - mainly Chinese - have been victimized by xenophobia and social stigmatization, with immense levels of threats online and during public interactions (Pakenham et al. 2020). With such reaction from developed and civilized countries, in nations such as Pakistan, where most of the population is still illiterate, this stigmatization specifically towards affected individuals and their families is on the rise. Therefore, it is essential for mental health professionals, including psychiatrists and psychologists, to act as an unbiased voice of reason and assist in educating the general masses to reduce their fear and stigmatization towards affected individuals and Chinese communities (Khalil et al. 2020).

\section{Prevalence of conspiracy theories about medication and panic-induced behavior}

At present, the scientists are not successful in developing a vaccine to precent the coronavirus infection; however, general-public feels a sense of medical distrust, which has resulted in poor condition of the healthcare facilities in managing health emergency circumstances (Ramanathan et al. 2020). Besides, health facilities distrust specifies a linkage to many infectious diseases and disorders, including and disparities based on ethnicity and race health (Cristian et al. 2020). Another important aspect that often appears alongside medical mistrust during pandemics is conspiracy theories (Quinn et al. 2018). Studies have shown several instances in which participants held a false belief relating to preventive health (Husnayain et al. 2020). It can lead to enforce public movements until the anti-vaccination trends during the epidemic outbreak (Jolley \& Douglas 2014). It shows the enforcement of stigmatization and lesser adherence to health recommendations. One prime example is in Pakistan, where many of the citizens still have a general mistrust towards using medicines and prefer herbal or home remedies while simultaneously avoiding mental health professionals due to a lack of knowledge, belief in myths, and fear of being stigmatized. A similar situation occurred with polio in Pakistan, where conspiracy theories led to many Pakistani people rejecting polio vaccinations (Andrade \& Hussain 2018). For this reason, the media, along with officials, should appear publicly and educate people about the importance and existence of physical health issues. Likewise, mental health issues during a pandemic, along with medical and mental health professionals giving scientific and factbased presentations and suggestions while addressing the importance of coronavirus control practices (Liu et al. 2020).

Any uncertain situation can lead to panic-induced behavior, and with the influence of coronavirus, selfconfinement and an absence of proper treatment for the infectious disease has led to a panic and anxiety-inciting situation (Zastepa et al. 2020). Although the anxiety symptoms may not reach the diagnostic threshold of the DSM-5, reassurance from mental health professionals can still help individuals to cope with their current anxieties. Likewise, persistent contamination obsession unwanted discomfort regarding one's cleanliness and a constant need to wash or sterilize oneself is usually classified under obsessive-compulsive disorder (Williams et al. 2013). In the case of a pandemic brought on by an infectious virus, this form of OCD can enhance panic, resulting in the disruption and operative impairment of individuals. It should need a careful check, as in countries such as Pakistan; typically, individuals do not remain registered with mental health experts and can suffer indefinitely in such circumstances (Ahmad et al. 2020). Clinical psychologists and mental health experts should be attentive to such impending issues and try to resolve them with the utmost care.

\section{CONCLUSION}

As the pandemic of coronavirus has spread fear on not only an individual but at a societal level, there is a need to implement proper mental health precautions along with physical health precautions, particularly in underdeveloped countries, like Pakistan. These countries have limited resources, and the healthcare systems are not highly developed or advanced for timely disease detection. The tackling of mental health problems is in high demand now. The health experts can help patients as well as suspects to avoid and alleviate long-term spread of (SARS-CoV-2) infectious disease. Other strategies, for instance, online psychological helplines, 
can also apply by working from home. It would offer easy access to the public to seek mental health advice from psychologists, and other health professionals' and the masses can easily maintain their communication to gain required assistance. The critical issue to respond affectively recommends the extensive testing at a larger scale, tracing transmitters, strict emphasis on care and home diagnosis. Besides, there is a great need for healthcare, medical professionals, and other paramedical staff care and protection, as they are fighting at the front against this deadly infectious disease worldwide. The rapid increase and fast speed of this outbreak are challenging healthcare systems worldwide, and the required pace to tackle this epidemic seems exponentially quicker than bureaucratic procedures in health systems. There is a greater need for learning to identify the most suitable approach to sustain and control the coronavirus pandemic worldwide until vaccination reaches to prevent the disease. Therefore, the preventive strategies' are useful, such as mitigation and suppression in the prevailing situation of a health emergency.

\section{Acknowledgements:}

The author is thankful to the school of Media and Communication, Shanghai Jiao Tong University (SJTU), to support this study. Professor Li Ben-qian and Professor Ling Jinzhu supervised this project.

Conflict of interest: None to declare.

\section{References}

1. Abbas J, Aqeel M, Abbas J, Shaher B, Aman J, Sundas, J $\&$ Zhang W: The moderating role of social support for marital adjustment, depression, anxiety, and stress: Evidence from Pakistani working and nonworking women. $J$ Affect Disord 2019; 244: 231-238.

2. Abbas J, Aqeel M, Jaffar A, Nurunnabi $M \&$ Bano $S$ : Tinnitus perception mediates the relationship between physiological and psychological problems among patients. JExp Psychopathol 2019; 10:2043808719858559

3. Ahmad T, Khan M, Khan FM \& Hui J: Are we ready for the new fatal coronavirus: scenario of Pakistan? Hum Vaccin Immunother 2020; 16:736-738

4. Ahmed SF, Quadeer AA \& McKay MR: Preliminary Identification of Potential Vaccine Targets for the coronavirus Coronavirus (SARS-CoV-2) Based on SARS-CoV Immunological Studies. Viruses 2020; 12:254

5. Andrade GE \& Hussain A: Polio in Pakistan: Political, Sociological, and Epidemiological Factors. Cureus 2018; 10:e3502

6. Cao W, Fang Z, Hou G, Han M, Xu X, Dong J \& Zheng J: The psychological impact of the coronavirus epidemic on college students in China. Psychiatry Research 2020; 287:112934

7. Chang JJ \& Ashcraft AM: Human Immunodeficiency Virus in Adolescents: Risk, Prevention, Screening, and Treatment. Prim Care 202;47:351-365
8. Cortegiani A, Ingoglia G, Ippolito M, Giarratano A \& Einav S: A systematic review on the efficacy and safety of chloroquine for the treatment of COVID-19. J Crit Care 2020; 57:279-283

9. Cristian FB, Koppel A, Janssen J, Utikal JS, Rappold GA, $\&$ Berkel S: Generation of two hiPSC lines from a patient with autism spectrum disorder harboring a $120 \mathrm{~kb}$ deletion in SHANK2 and two control lines from each parent. Stem Cell Res 2020; 49:102004

10. Folkman $S$ \& Greer S: Promoting psychological wellbeing in the face of serious illness: when theory, research, and practice inform each other. Psycho-Oncology 2000; 9:11-19

11. Gale SD, Berrett AN, Erickson LD, Brown BL \& Hedges $D W$ : Association between virus exposure and depression in US adults. Psychiatry Res 2018; 261:73-79

12. Halle C, Tzani-Pepelasi C, Pylarinou NR \& Fumagalli A: The link between mental health, crime, and violence. New Ideas in Psychology 2020; 58:100779

13. Huang Z, Zhao S, Li Z, Chen W, Zhao L, Deng L \& Song B: The Battle Against coronavirus Disease 2019 (coronavirus): Emergency Management and Infection Control in a Radiology Department. J Am Coll Radiol 2020; 17:710-716

14. Husnayain A, Fuad A \& Su EC: Applications of google search trends for risk communication in infectious disease management: A case study of coronavirus outbreak in Taiwan. Int J Infect Dis 2020; 95:221-223

15. Johnson NP \& Mueller J: Updating the accounts: global mortality of the 1918-1920 "Spanish" influenza pandemic. Bull Hist Med 2002; 76:105-115.

16. Jolley D \& Douglas KM: The effects of anti-vaccine conspiracy theories on vaccination intentions. PLoS One 2014; 9:e89177

17. Khalil A, Gondal F, Imran $N$ \& Azeem MW: SelfStigmatization in children receiving mental health treatment in Lahore, Pakistan. Asian J Psychiatr 2020; 47:101839

18. Kott $A$ \& Limaye RJ: Delivering risk information in a dynamic information environment: Framing and authoritative voice in Centers for Disease Control (CDC) and primetime broadcast news media communications during the 2014 Ebola outbreak. Social Science \& Medicine 2016; 169:42-49

19. Li W, Yang Y, Liu ZH, Zhao YJ, Zhang Q, Zhang L, Cheung T \& Xiang YT: Progression of Mental Health Services during the coronavirus Outbreak in China. Int $J$ Biol Sci 2020; 16:1732-1738

20. Liu N, Zhang F, Wei C, Jia Y, Shang Z, Sun L et al.: Prevalence and predictors of PTSS during coronavirus Outbreak in China Hardest-hit Areas: Gender differences matter. Psychiatry Res 287:11292

21. Liu WH, Guo SN, Wang F \& Hao Y: Understanding of Guidance for acupuncture and moxibustion interventions on coronavirus (Second edition) issued by the China Association of Acupuncture-Moxibustion. World Journal of Acupuncture-Moxibustion 2020; 30:1-4

22. Mak IW, Chu CM, Pan PC, Yiu MG \& Chan VL: Longterm psychiatric morbidities among SARS survivors. Gen Hosp Psychiatry 2009; 31:318-326

23. Mason BW \& Lyons RA: Acute psychological effects of suspected bioterrorism. J Epidemiol Community Health 2003; 57:353-354 
24. Maya-Mondragon J, Sanchez-Roman FR, Palma-Zarco A, Aguilar-Soto M \& Borja-Aburto VH: Prevalence of Posttraumatic stress disorder and depression after the September 19(th), 2017 earthquake in Mexico. Arch Med Res 2019; 50:502-508

25. WHO: Coronavirus disease (COVID-2019) situation reports. Available on: https://www. WHO. Int/docs/default-source/ coronaviruse/situation-reports/20200221-sitrep-32coronavirus

26. Pakenham KI, Landi G, Boccolini G, Furlani A, Grandi $S$ \& Tossani E: The moderating roles of psychological flexibility and inflexibility on the mental health impacts of COVID-19 pandemic and lockdown in Italy. J Contextual Behav Sci 2020; 17:109-118

27. Quinn KG, Kelly JA, DiFranceisco WJ, Tarima SS, Petroll $A E$, Sanders $C$, Lawrence JSS \& Amirkhanian YA: The Health and Sociocultural Correlates of AIDS Genocidal Beliefs and Medical Mistrust Among African American MSM. AIDS Behav 2018; 22:1814-1825

28. Ramanathan $K$, Antognini D, Combes A, Paden $M$, Zakhary B, Ogino $M$ et al.: Planning and provision of ECMO services for severe ARDS during the coronavirus pandemic and other outbreaks of emerging infectious diseases. Lancet Respir Med 2020; 8:518-526

29. Reperant LA \& Osterhaus A: AIDS, Avian flu, SARS, MERS, Ebola, Zika... what next? Vaccine 2017; 35:4470-4474

30. Rubin GJ \& Wessely S: The psychological effects of quarantining a city. BMJ 2020; 368:m313

31. Shuja KH, Aqeel M, Jaffar A \& Ahmed A: Coronavirus Pandemic and Impending Global Mental Health Implications. Psychiatr Danub 2020; 32:32-35

32. Shuja KH, Shahidullah Aqeel M, Khan EA \& Abbas J. Letter to highlight the effects of isolation on elderly during COVID-19 outbreak. Int J Geriatr Psychiatry 2020; https://doi.org/10.1002/gps.5423

33. Shultz JM, Cooper JL, Baingana F, Oquendo MA, Espinel Z, Althouse BM et al.: The Role of Fear-Related Behaviors in the 2013-2016 West Africa Ebola Virus Disease Outbreak. Curr Psychiatry Rep 2016; 18:104
34. Silverio A, Di Maio $M$, Ciccarelli $M$, Carrizzo A, Vecchione $C \&$ Galasso G: Timing of national lockdown and mortality in COVID-19: The Italian experience. Int $J$ Infect Dis 2020; 100:193-195

35. Su Z, Wen J, Abbas J, McDonnell D, Cheshmehzangi, A Li $X$, Ahmad J, Šegalo $S$ et al.: A race for a better understanding of COVID-19 vaccine non-adopters. Brain, Behavior \& Immunity - Health 2020; 9:100159

36. Van Den Heuvel L, Chishinga N, Kinyanda E, Weiss H, Patel $V$, Ayles $H$ et al.: Frequency and correlates of anxiety and mood disorders among TB-and HIV-infected Zambians. AIDS care 2013; 25:1527-1535

37. Wang $Y$, Wang $Y$, Chen $Y$ \& Qin Q: Unique epidemiological and clinical features of the emerging 2019 novel coronavirus pneumonia (COVID-19) implicate special control measures. J Med Virol 2020; 92:568-576

38. Williams MT, Mugno B, Franklin M \& Faber S: Symptom dimensions in obsessive-compulsive disorder: phenomenology and treatment outcomes with exposure and ritual prevention. Psychopathology 2013; 46:365-376

39. Xiang Y-T, Yang Y, Li W, Zhang L, Zhang Q, Cheung $T$ \& $\mathrm{Ng} \mathrm{CH}$ : Timely mental health care for the 2019 novel coronavirus outbreak is urgently needed. The Lancet Psychiatry 2020; 7:228-229

40. Yoosefi Lebni J, Abbas J, Moradi F, Salahshoor MR, Chaboksavar F, Irandoost SF, Nezhaddadgar $N$ \& Ziapour A: How the COVID-19 pandemic effected economic, social, political, and cultural factors: A lesson from Iran. Int $J$ Soc Psychiatry 2020; 66:20764020939984

41. Zastepa E, Sun JC, Clune J \& Mathew N: Adaptation of contingency management for stimulant use disorder during the COVID-19 pandemic. Journal of Substance Abuse Treatment 2020; 118:108102

42. Zhao S, Lin Q, Ran J, Musa SS, Yang G, Wang Wet al.: Preliminary estimation of the basic reproduction number of novel coronavirus (2019-nCoV) in China, from 2019 to 2020: A data-driven analysis in the early phase of the outbreak. Int J Infect Dis 2020; 92:214-217

Correspondence:

Jaffar Abbas

Antai College of Economics and Management (ACM), School of Media and Communication (SMC),

Shanghai Jiao Tong University (SJTU)

No. 800 Dongchuan Road, Minhang District, Postcode 200240, Shanghai, China

E-mail: abbas512@sjtu.edu.cn 